\title{
FLORA DE GRÃO-MOGOL, MINAS GERAIS: PALMAE (ARECACEAE) ${ }^{1}$
}

\author{
AMAURI CÉSAR MARCATO \& JOSÉ RUBENS PIRANI
}

Departamento de Botânica, Instituto de Biociências, Universidade de São Paulo, Caixa Postal 11461, 05422-970 - São Paulo, SP, Brasil.

Dransfield, J. 1995. Palmae. In B.L. Stannard (ed.) Flora of the Pico das Almas, Chapada Diamantina - Bahia, Brazil. Royal Botanic Gardens. Kew, p. 768-770.

Glassman, S.F. 1987. Revision of the palm genus Syagrus Mart. and other selected genera in the Cocos alliance. Illinois Biol. Monogr. 56: 1-230.

Henderson, A., Galeano, G. \& Bernal, R. 1995. Field guide to the palms of the Americas. Princeton University Press, Princeton.

Marcato, A.C. \& Pirani, J.R. 2001. Flora da Serra do Cipó, Minas Gerais: Palmae (Arecaceae). Bol. Bot. Univ. São Paulo 19: $45-54$. Moraes, R.M. 1996. Allagoptera (Palmae). Fl. Neotrop. Monogr. 73: 1-34.

Uht, N. \& Dransfield, J. 1987. Genera Palmarum. Allen Press. Lawrence, Kansas.

Reitz, R. 1974. Palmeiras. In R. Reitz (ed.) Flora Ilustrada Catarinense. Herbário Barbosa Rodrigues. Itajaí.

1. Folhas costapalmadas. Mauritia flexuosa

1'. Folhas pinadas.

2. Caule curto e pouco evidente ou subterrâneo.

3. Raque foliar maior que $200 \mathrm{~cm}$, folíolos ca. $90-92$. Attalea geraensis

3'. Raque foliar menor que $100 \mathrm{~cm}$, folíolos 27-68.

4. Folíolos ca. 68; inflorescência espiciforme congesta com flores numerosas, apresentando uma porção apical somente com flores estaminadas

4'. Folíolos 27-34; inflorescência espiciforme ou ramificada, mas sempre com número reduzido de flores.

Allagoptera campestris

2'. Caule aéreo bem evidente.

5. Diâmetro do estipe menor que $10 \mathrm{~cm}$.

6. Folíolos ca. 63, flácidos, dispostos em diferentes planos, ramos da inflorescência reflexos, ausentes na face adaxial da raque; frutos 3-3,5 x 1,6-1,8 cm; em cerrado

6'. Folíolos ca. 38, eretos, dispostos no mesmo plano, ramos da inflorescência com disposição actinomorfa; frutos $1 \times 1 \mathrm{~cm}$; em matas de galeria......

Syagrus petraea Diâmetro do estipe maior que $20 \mathrm{~cm}$.

7. Folhas densamente espinescentes na raque; frutos depresso-globosos

7'. Folhas inermes; frutos alongados a obovóides.

8. Folíolos dispostos dispostos em vários planos, bainhas foliares decíduas

8'. Folíolos dispostos em um ou dois planos, bainhas foliares marcescentes.

9. Plantas massivas 5-14 m alt., folhas mais ou menos eretas; folíolos dispostos em um só plano, ca. 141; frutos 6-6,5 x 3,8-4,5 cm Attalea oleifera

9'. Plantas até $4 \mathrm{~m}$ altura, folhas arqueadas; folíolos dispostos em "v", ca. 60; frutos $2,4-2,7 \times 1,1-1,3 \mathrm{~cm}$ Butia capitata

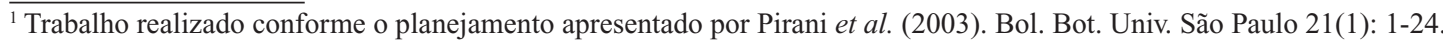




\section{Acrocomia Mart.}

Plantas monóicas. Caule solitário, aéreo. Folhas dispostas espiraladamente, armadas com emergências espiniformes, pinadas, arqueadas, pecíolo curto a longo, raque longa; folíolos numerosos, lineares, ápice acuminado assimétrico, dispostos em vários planos, flácidos, conferindo a folha aparência plumosa. Inflorescência bissexuada com raquilas numerosas, bráctea peduncular lenhosa, densamente pilosa, com ou sem espinhos esparsos; estames-6, gineceu 3-locular, 1-2 ovulado. Fruto depresso-globoso, epicarpo liso, mesocarpo carnoso, endocarpo lenhoso muito duro, poros-3, próximos ao equador, sementes 1-2, endosperma homogêneo.

1.1. Acrocomia aculeata (Jacq.) Lodd. ex Mart., Hist. nat. palm. 3: 286. 1849.

Nome vulgar: macaúba.

Plantas até $10 \mathrm{~m}$ alt. Caule cinéreo, bases foliares persistentes. Folhas ca. 15, marcescentes; bainha fortemente espinescente; pecíolo indistinto; raque espinescente, ca. 1,9 m compr.; folíolos ca. 181, algumas vezes com emergências na face abaxial ou adaxial, folíolo mediano ca. $65 \mathrm{~cm}$ compr., 2,8 cm larg. Inflorescência: bráctea peduncular ca. 1,6 m compr.; pedúnculo ca. $10 \mathrm{~cm}$, raque ca. $93 \mathrm{~cm}$, raquilas ca. 230 . Flores estaminadas amareladas, $8 \mathrm{~mm}$ compr., $5 \mathrm{~mm}$ larg.; sépalas $2 \mathrm{~mm}$ compr., pétalas ca. $6 \mathrm{~mm}$ compr., $4 \mathrm{~mm}$ larg.; flores pistiladas castanho-avermelhadas, 10 compr., $10 \mathrm{~mm}$ larg.; sépalas $3 \mathrm{~mm}$ compr., $5 \mathrm{~mm}$ larg.; pétalas $8 \mathrm{~mm}$ compr., $9 \mathrm{~mm}$ larg. Fruto globoso a levemente depresso-globoso, 3-5,7 cm compr., 3,2-6,5 cm diâm., perianto persistente castanho-escu- ro, anel de estaminódios $5 \mathrm{~mm}$ alt., epicarpo fino, liso, raro tomentoso-hirsuto, castanho-amarelado a castanho-escuro, coloração não uniforme quando imaturo, $1 \mathrm{~mm}$ espessura, mesocarpo carnoso-fibroso, 5-6 mm espessura, fibras curtas, não agrupadas; sementes 1-2, 1,8-2,4 cm compr., 2,3-3 cm diâm., algumas vezes lateralmente achatadas. (Fig. 1. A-B)

Marcato et al. 199 (SPF).

Material adicional: Minas Gerais, Jaboticatubas, Marcato et al. 34 (SPF); Santana do Riacho, Pirani et al. CFSC 11050 (SPF).

Espécie de ampla distribuição, ocorrendo do sul do Brasil (São Paulo), Paraguai e Argentina até o sul do México e Antilhas, normalmente em áreas abertas, como cerrados e campos, até ca. de $1200 \mathrm{~m}$ alt. Em Grão-Mogol, ocorre em encosta com cerrado e campo rupestre. Coletada com frutos imaturos em maio.

\section{Allagoptera Nees}

Plantas monóicas, inermes. Caule solitário, subterrâneo a decumbente, raro cespitoso. Folhas dispostas espiraladamente, pinadas; pecíolo curto a longo; folíolos numerosos, lineares, ápice lobado ou acuminado, assimétrico, irregularmente dispostos, divergindo em vários ângulos. Inflorescência espiciforme, bissexuada ou raro unissexuada; bráctea peduncular lenhosa e sulcada; estames 6-18, gineceu 3-locular, 3-ovulado. Fruto ovóide, elipsóide a turbinado, epicarpo e mesocarpo delgados, endocarpo lenhoso duro, poros 3 , próximos à base do endocarpo; semente 1 por fruto, endosperma homogêneo.

2.1. Allagoptera campestris (Mart.) Kuntze, Revis. gen. pl. 2: 726.1891.

Nome vulgar: coco-de-vassoura.

Plantas 0,4-1,5 m alt. Caule subterrâneo. Folhas 4-7; pecíolo e bainha 5-33 cm compr., 0,5-1,3 cm larg.; raque $34-81 \mathrm{~cm}$ compr.; folíolos 34-69, curto-lanceolados, ápice acuminado, rígidos e eretos, em grupos de 2-3, inseridos divergentemente na raquila; folíolo mediano $14-46 \mathrm{~cm}$ compr., $0,5-1,8 \mathrm{~cm}$ larg. Inflorescência: profilo 16,5-22 cm compr., 1,5-2,2 cm larg.; bráctea peduncular basal $20-80 \mathrm{~cm}$ compr. total e $18-50 \mathrm{~cm}$ compr., 1,8-3 cm larg. na porção expandida; rostro 0,7-3,5 cm compr.; brácteas pedunculares distais 1-2, escariosas, dentadas, 1,3-8,5 cm compr., próximas ao ápice do pedúnculo; pedúnculo 6-72 cm compr., 0,4-0,6 cm larg.; raque 6-25 cm compr. total e 3$10,5 \mathrm{~cm}$ compr. na porção pistilada. Flores estaminadas creme, ca. 7 mm compr.; sépalas 3-7 mm compr., 1-2 mm larg., glabras, coriáceas; pétalas 5-7 mm compr., 3-4 mm larg.; estames 6, anteras 2-4 mm; flores pistiladas inseridas até 3-10,5 cm na raque; sépalas livres, 5-6 mm compr., 3-4 mm larg.; pétalas 4-6 $\mathrm{mm}$ compr., 3-4 mm larg. Fruto ovóide a elipsóide, 1,1-1,5 cm compr., 0,8-1,2 cm diâm., epicarpo estriado longitudinalmente, endocarpo ca. $1 \mathrm{~mm}$, lenhoso. (Fig. 1. C-D)

Ferreira et al. 703 (RB); Marcato et al. 198, 314 (SPF); Martinelli et al. $11240(\mathrm{RB})$;.

Ocorre da Bahia e Goiás a São Paulo e nordeste da Argentina, em áreas de cerrado, campo sujo e campo rupestre, em altitudes entre 600-1500 m (Moraes 1996). Em GrãoMogol ocorre em áreas de cerrado. Coletada com flores em janeiro e frutos imaturos em maio. 


\section{Attalea Kunth}

Plantas monóicas, inermes. Caule solitário ou raramente cespitoso, curto e subterrâneo a longo e aéreo. Folhas dispostas espiraladamente, ascendentes a arqueadas, pinadas; pecíolo curto a longo; folíolos numerosos, lineares, ápice aristado ou lobado, assimétrico. Inflorescência ramificada, com flores todas estaminadas, ou estaminadas e pistiladas, ou predominantemente pistiladas na mesma planta; bráctea peduncular naviculada, rostrada, lenhosa, estriada; estames 6-75; gineceu com 3-vários lóculos e óvulos. Frutos de formas variadas, endocarpo duro e lenhoso, com ou sem fibras; sementes 1-várias, endosperma homogêneo.

3.1. Attalea geraensis Barb. Rodr., Pl. jard. Rio de Janeiro 6: 22, t. 7. 1898.

Nome vulgar: catolé.

Plantas até ca. 1,2 m alt. Caule curto a subterrâneo. Folhas 4-10, ligeiramente arqueadas; pecíolo e bainha curtos ou pecíolo 76-165 cm compr.; raque 1,4-2,9 m; folíolos 83 126, lineares, ápice assimétrico, dispostos no mesmo plano. Inflorescência estaminada com bráctea $53-75 \mathrm{~cm}$, pedúnculo ca. $30 \mathrm{~cm}$, raque $20-22 \mathrm{~cm}$, raquilas ca. $86,27,8-41,3$ mm compr.; flores estaminadas creme arranjadas em duas linhas de raquilas ao longo da raque, amarelo-escuras, ca. 15,5 mm compr., 5,2 $\mathrm{mm}$ larg., sépalas 2,7 mm compr., 1,8 mm larg., acuminadas, pétalas 15,2 mm compr., $3 \mathrm{~mm}$ larg., assimétricas, ápice acuminado, pistilódio menor que $1 \mathrm{~mm}$, trífido; inflorescência pistilada com bráctea ca. 70 cm compr., $9 \mathrm{~cm}$ larg., pedúnculo ca. $15 \mathrm{~cm}$, raque ca. 23 cm compr., raquilas ca. 68 , 46-53 mm compr., flores pistiladas 2,2-2,9 cm compr., sépalas ca. 25,2 mm compr., $35 \mathrm{~mm}$ larg., pétalas ca. $26 \mathrm{~mm}$ compr., 36,1 mm larg., estigmas 3. Frutos ca. 25, ovóide-elipsóides, acuminados, verde-ocráceos quando imaturos, $6 \mathrm{~cm}$ compr., $3,5 \mathrm{~cm}$ diâm., cálice e corola persistentes, atingindo ca. metade do comprimento do fruto; sementes 2. (Fig. 1. F)

Ocorre nos cerrados ou matas secas em solos arenosos, da Bahia a São Paulo. Em Grão-Mogol, aparece em formação arbóreo-arbustiva densa. Foi coletada com flores e frutos imaturos em maio.

Marcato et al. 197, 206 (SPF); Pirani \& Mello-Silva CFCR 10809 (MAC, SPF); Rapini \& Kawasaki 749 (SPF)

3.2. Attalea oleifera Barb. Rodr., Rev. Braz. 7: 123. 1881; tab. 58. 1903.

Nome vulgar: andaiá.
Plantas 5-14 m alt. Caule 1,7-7 m alt., 0,30-0,40 m diâm. Folhas 8-19, ligeiramente arqueadas; bainha e pecíolo 37-62 cm compr., margens fibrosas; raque 4,01-6,30 m compr.; folíolos 141-193, regularmente distribuídos em um plano, mediano 92-114 cm compr., 4,8-7 cm larg., ápice acuminado assimétrico. Inflorescência: profilo não examinado; bráctea peduncular lepidota, cinérea, compr. total 1,7-2 m compr., porção expandida ca. $36 \mathrm{~cm}$ compr., $6 \mathrm{~cm}$ larg., rostro 3,8-11 cm compr., pedúnculo $20-73 \mathrm{~cm}$ compr., 4-5 cm diâm., raque $38-99 \mathrm{~cm}$ compr., raquilas 21-30, até $5 \mathrm{~cm}$ compr., estaminada com raquilas secundifloras. Flores amarelo-claras $16 \mathrm{~mm}$ compr., $7 \mathrm{~mm}$ larg., sépalas 1,7 mm compr., 1,2 mm larg., pétalas $16,7 \mathrm{~mm}$ compr., 4,5 mm larg.; estames 6-9, anteras ca. 9 mm compr., pistilódio trífido; inflorescência bissexuada com flores estaminadas estéreis, flores pistiladas ca. 35,1 mm compr., 17,5 mm larg., sépalas $24,5 \mathrm{~mm}$ compr., $16,8 \mathrm{~mm}$ larg., pétalas $25,4 \mathrm{~mm}$ compr., 15,9 mm larg. Fruto 5-6,2 cm compr., 3,6-3,8 cm diâm., perianto cupuliforme castanho-cinéreo, 30-35 mm compr., epicarpo liso coberto por indumento castanho-escuro até $1 \mathrm{~mm}$ espessura, mesocarpo castanho-amarelado, fibroso, 1-2 mm espessura, endocarpo lenhoso duro, 5-10,5 $\mathrm{mm}$ espessura, fibras circularmente dispostas; semente 1-2, endosperma homogêneo, poros próximos da base do endocarpo. (Fig. 1. G-H)

Marcato et al. 203 (SPF).

Material complementar : Minas Gerais, Rio Vermelho, Marcato et al. 118 (SPF); Congonhas do Norte, Marcato et al. 175 (SPF); Botumirim, Marcato et al. 210 (SPF).

Ocorre desde a costa do Estado da Paraíba até São Paulo, possivelmente atingindo áreas de transição rumo ao cerrado, no interior do continente. Em Grão-Mogol ocorre próximo a área com mata semidecídua. Coletada com frutos em maio.

\section{Butia (Becc.) Becc.}

Plantas monóicas. Caule solitário, aéreo. Folhas dispostas espiraladamente, pinadas, fortemente arqueadas, pecíolo curto a longo, raque longa; folíolos numerosos, lineares, ápice acuminado assimétrico, dispostos em "v" na seção transversal. Inflorescência bissexuada com poucas a numerosas raquilas; bráctea peduncular naviculada, lisa, lenhosa, glabra a tomentosa; estames-6, gineceu 3-locular, 3 ovulado. Fruto oblato a ovóide, epicarpo liso, mesocarpo carnoso, endocarpo lenhoso muito duro, poros 3, próximos ao equador; sementes 1-2, endosperma homogêneo. 
4.1. Butia capitata (Mart.) Becc., Agric. Colon. 507, t.5, figs. 7-8. 1916.

Nome vulgar: butiá, coquinho-azedo.

Plantas até 2,6 m alt. Caule 0,5-1,6 m alt., ca. $20 \mathrm{~cm}$ diâm. Folhas 7-15; pecíolo e bainha $25-58 \mathrm{~cm}$ compr., margens com fibras achatadas duras, fortemente dentiformes; raque 88-155 cm compr.; folíolos 40-60, mediano 43-60 cm compr e 1,2-2,2 cm larg., ápice acuminado. Inflorescência: profilo ca. $22 \mathrm{~cm}$; bráctea peduncular lenhosa, relativamente lisa, verde-escuro na inflorescência jovem mas tornando-se castanha, $50-100 \mathrm{~cm}$, rostro $2-2,5 \mathrm{~cm}$; pedúnculo 40 , raque 33-47 $\mathrm{cm}$, raquilas ca. 70, 9-22 cm compr., brácteas das raquilas ca. $1 \mathrm{~mm}$ compr. Flores estaminadas dispostas espiraladamente em tríades e principalmente em díades e solitárias na porção distal da raquila, amarelas, ca. 7,5 mm compr., $6 \mathrm{~mm}$ larg., sépalas e pétalas valvares, sépalas ca. 3,1 mm compr., 0,6 mm larg., pétalas 3,9 mm compr., 1,8 mm larg., ápice acuminado; estames 6 , anteras ca. 2,9 mm compr., filetes ca. 2,7 mm compr., pistilódio ca. $4,3 \mathrm{~mm}$; flores pistiladas amarelas, 4,8-5,6 mm compr., 3,6-3,9 mm larg., sépalas e pétalas 3, sépalas ca. 5,3 mm compr., 3,6 $\mathrm{mm}$ larg., ápice acuminado, pétalas imbricadas, ca. 3,9 $\mathrm{mm}$ compr., 3,2 $\mathrm{mm}$ larg., ápice acuminado, anel de estaminódios ca $1 \mathrm{~mm}$ compr. Fruto ca. 26 mm comrp., $11 \mathrm{~mm}$ diâm., perianto persistente, ca. $5 \mathrm{~mm}$, anel composto por 4-6 estaminódios, 1-2 mm alt., epicarpo liso mas fibroso, amarelo brilhante quando maduro, menor que $1 \mathrm{~mm}$ espessura, mesocarpo carnoso, fibroso e amarelo, ca. $2 \mathrm{~mm}$ espessura, endocarpo lenhoso, castanho-escuro com 1-2 lóculos, ca. 3 mm espessura; sementes 1-2. (Fig. 1. E)

Marcato et al. 311 (SPF).

Material complementar: Minas Gerais, Bocaiúva, Marcato et al. 105 (SPF); Cristália, Marcato et al. 209 (SPF); Mato Verde, Marcato et al. 184, 185 (SPF).

Esta espécie ocorre da Bahia e Goiás ao Uruguai (Henderson et al. 1995), em áreas de cerrado ou terrenos arenosos, como dunas e restingas (Reitz 1974). Em Grão-Mogol, ocorre em áreas de cerrado ou próximo a mata semidecídua. Coletada estéril em maio e em outras localidades com flores e frutos imaturos em maio, no início do período de seca.

\section{Geonoma Willd.}

Plantas de pequenas a médias. Caule geralmente delgado. Folhas dispostas espiraladamente, 7-25, simples ou pinadas; folíolos de poucos a muitos dispersos no mesmo plano, lineares ou sigmóides. Inflorescências bissexuadas, axilares, infrafoliares na maturação, em espiga simples ou ramificadas; profilo similar à bráctea peduncular, papiráceos a subcoriáceos. Flores em tríades em pequenas cavidades, decussadas ou espiraladamente dispostas; Flores estaminadas com 7-12 estames; Gineceu 3carpelar, unilocular e uniovular. Fruto pequeno, globoso a elipsóide, atropurpúreo; semente 1; endosperma homogêneo.

5.1. Geonoma brevispatha Barb. Rodr., Prot. App. Enum. Pal. Nov. 41. 1879; tab. 22, 31B. 1903.

Nome vulgar: ouricana.

Plantas medianas, solitárias a cespitosas, 1,5-6 m alt. Caule ereto a arqueado, até $3 \mathrm{~m}$ alt., 1,5-6 cm diâm. Folhas 6-18, pinadas; bainhas $12-33 \mathrm{~cm}$, mais ou menos fibrosas; pecíolo (4)25-77 cm compr., 0,4-1 cm larg., margens lisas, canaliculadas; raque 19,3-129 cm compr; folíolos 6-38, regular ou irregularmente distribuídos em 1 plano, mediano $13-58 \mathrm{~cm}$ compr., 0,5-7 cm larg., ápice na maioria das vezes acuminado a sigmóide. Inflorescência ramificada até segunda ordem; profilo coriáceo, 7,2-24 cm compr., ca. 2,5 cm larg; bráctea da inflorescência papirácea, inserida 0,6-13 $\mathrm{cm}$ acima do profilo, 5,5-19,8 cm compr.; pedúnculo 12-45 cm compr. e 2,5-6 mm diâmetro; raque 2,5-41 cm compr.; raquilas 5-24, 7-28 cm compr., 1,2-3,2 mm diâm.; tríades decussadas a alternas. Flores estaminadas ca. 0,45 mm compr., 0,4 mm larg., sépalas distintas, 2-2,5 mm compr., $1 \mathrm{~mm}$ larg., livres, carenadas, ápice agudo, valvares, pétalas ca. 2 mm compr., $1 \mathrm{~mm}$ larg., ápice agudo; estames 6, anteras 1 mm compr, filetes unidos em tubo estaminodial na base e então a parte livre reflexa, ca. $2 \mathrm{~mm}$ compr.; flores pistiladas exsertas na antese, sépalas e pétalas 3, sépalas basalmente conatas e lobos levemente imbricados, ca. $3 \mathrm{~mm}$ compr., 1,5 mm larg., estigmas 3 , róseos, ca. $1 \mathrm{~mm}$ compr., tubo estaminodial superficialmente crenulado e 6-lobado, odor azedo. Fruto 6,5-9 mm compr., 7-7,5 mm diâm., epicarpo liso, atropurpúreo quando maduro, fino, mesocarpo fibroso, fino, endocarpo cartilaginoso, fino; semente 1, esdosperma homogêneo. (Fig. 2. A-B)

Marcato et al. 201 (SPF); Pirani et al. CFCR 13530 (MAC, SPF).

Material complementar: Minas Gerais, Congonhas do Norte, Marcato et al. 158, 170 (SPF).

Esse táxon pertence a um complexo formado por várias espécies, as quais somente poderão ser melhor compreendidas após uma revisão do gênero como um todo (Dransfield 1995, Henderson et al. 1995).

Ocorre no interior de matas de galeria, do Tocantins ao Paraná. Em Grão-Mogol, foi coletada com flores em setembro. 


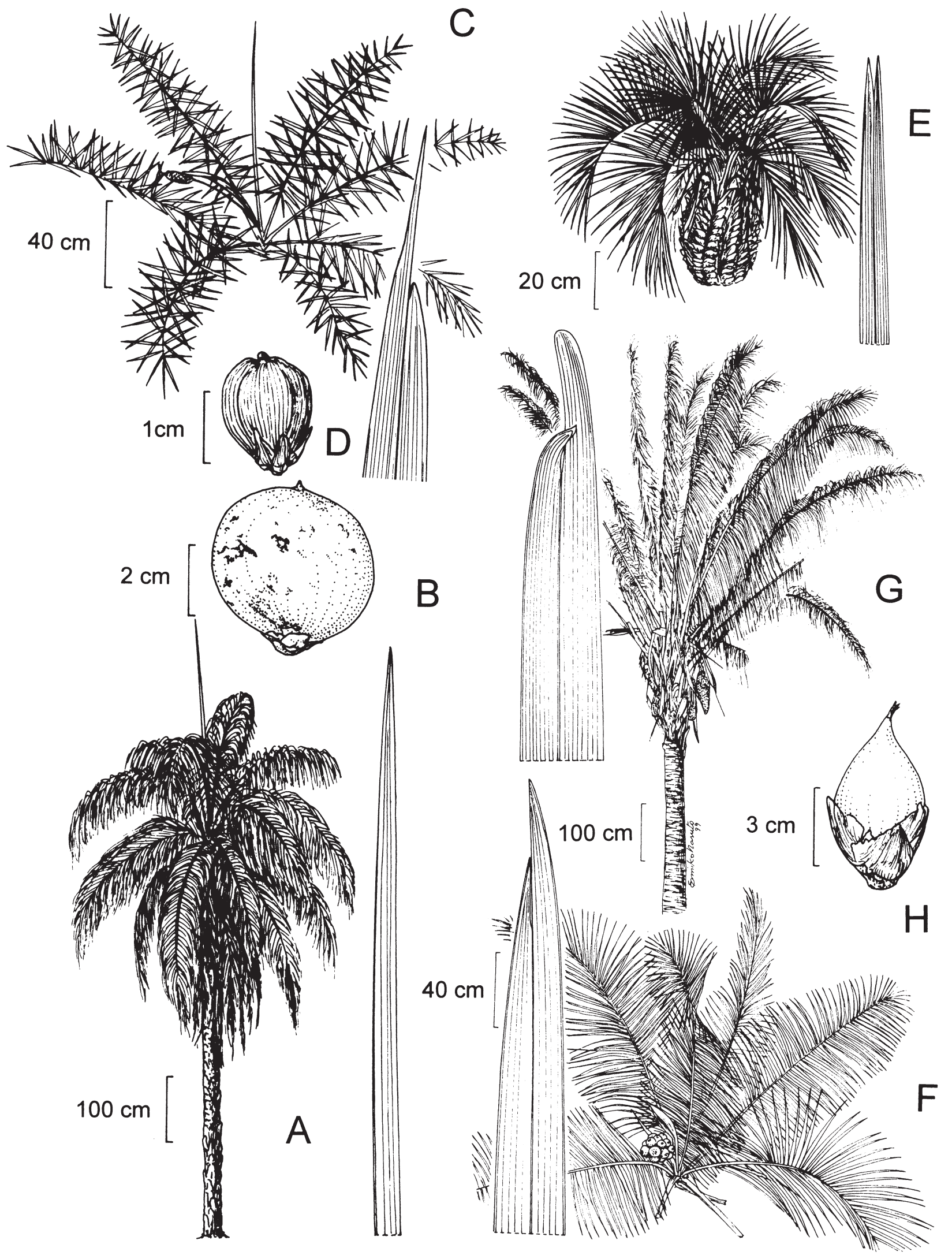

Fig. 1. PALMAE . A-B. Acrocomia aculeata: A. Hábito; B. Fruto. C- D. Allagoptera campestris: C. Hábito; D. Fruto. E. Butia capitata: Hábito. F. Attalea geraensis: Hábito. G-H. Attalea oleifera: G. Hábito; H. Fruto. 


\section{Mauritia L. f.}

Plantas dióicas, inermes. Caule solitário, ereto. Folhas espiraladamente dispostas, grandes, costa-palmadas; pecíolo liso, inerme; lâmina apresentando uma crista hastuliforme na base adaxial; lâmina orbicular, dividida em numerosos segmentos. Inflorescências estaminadas e pistiladas superficialmente similares; pedúnculo apresentando muitas brácteas dísticas sobrepostas; brácteas da raque numerosas embainhando completamente os ramos; raquila estaminada espiciforme pouco congesta com numerosas flores; raquila pistilada não espiciforme, com uma flor pistilada solitária. Flores estaminadas com cálice tubular levemente 3-lobado; estames 6; pistilódio diminuto; flores pistiladas maiores que as estaminadas; cálice tubular; estaminódios 6; gineceu trilocular, triovulado mais ou menos arredondado, coberto por linhas verticais de escamas. Fruto mais ou menos esférico, grande; epicarpo recoberto por escamas suavemente carenadas, castanho-avermelhadas lustrosas, mesocarpo espesso, carnoso, endocarpo não diferenciado; semente usualmente 1.

\subsection{Mauritia flexuosa L. f., Suppl. pl. 454. 1781. \\ Nome vulgar: buriti.}

Plantas até $15 \mathrm{~m}$ alt. Caule colunar, ca. $8 \mathrm{~m}$ alt., 30-40 cm diâm. Folhas ca. 12; costa $72-170$ cm compr., recurvada; segmentos verde-escuro lustrosos adaxialmente e glaucos abaxialmente com margens lisas, 115-131, distribuídos em 1 plano entre si mas os dois lados da folha em planos diferentes, medianos 1-2,3 m compr., 3-5,4 cm larg. e conatos por ca. um décimo do seu compr., a partir da base. Inflorescências várias por planta, estaminadas e pistiladas, $72-112 \mathrm{~cm}$ compr; pedúnculo ca. $1 \mathrm{~m}$ compr., $5 \mathrm{~cm}$ diâm., com várias brácteas pedunculares tubulares, raque com ca. 40 raquilas dísticas, ca. $1 \mathrm{~m}$ compr., flores em espiguetas curtas, disticamente dispostas em pequenos ramos da raquila; espiguetas estaminadas ca. $5 \mathrm{~cm}$ compr. Flores estaminadas alaranjadas; cálice tubular, levemente trilobado; corola composta por 3 pétalas conatas na base, ca. 6,2 mm compr., 2,2 mm larg.; estames-6, anteras 2,8 mm compr., filetes conatos na base; espiguetas pistiladas pouco desenvolvidos, ca. $1 \mathrm{~cm}$ compr. com poucas flores férteis; flores pistiladas ca. 1,5 cm compr.; cálice urceolado, levemente trilobado; corola tubular na metade inferior com a metade superior valvada; estaminódios 6; estigma apical. Fruto subgloboso a elíptico, 4-4,5 cm compr., 4-4,3 cm diâm., perianto persistente castanho-granuloso, ca. $10 \mathrm{~mm}$ compr., epicarpo coberto com escamas castanho-avermelhadas, mesocarpo laranja, carnoso, ca. 1 $\mathrm{mm}$ espessura, endocarpo lenhoso; semente subglobosa 1. (Fig. 2. C-D)

\author{
Marcato et al. 202 (SPF). \\ Material complementar: Minas Gerais, Joaquim Felício, Marcato \\ et al. 106 (SPF).
}

Ocorre por todo o norte da América do Sul e leste dos Andes, atingindo o estado de São Paulo como limite sul de distribuição. Forma as denominadas veredas, caracterizadas por grandes adensamentos dessas palmeiras ao longo de cusos d'água, nos domínios dos cerrados do Brasil Central.

$\mathrm{Na}$ região de Grão-Mogol, aparece às margens do rio Itacambiruçu próximo a áreas de floresta semidecídua e na Chapada do Bosque, praticamente na encosta NE da serra, habitando solos arenosos às margens de curso d'água, onde forma pequenas veredas. Coletada com frutos em maio.

\section{Syagrus Mart.}

Folhas dispostas espiraladamente, 6-30, pinadas; folíolos de poucos a numerosos, estreitos, lineares, glaucos ou verdes, rijos ou flexíveis, ápice agudo, acuminado ou obtuso, simétrico ou assimétrico. Inflorescências bissexuadas, interfoliares; bráctea peduncular persistente lenhosa e estriada. Flores estaminadas com 6 estames; gineceu 3-carpelar, unilocular, uniovular. Frutos ovóides, elipsóides ou globosos, pequenos; sementes 1-2; poros basais 3; endocarpo circular a triangular; endosperma homogêneo ou ruminado.

7.1. Syagrus flexuosa (Mart.) Becc., Agric. Colon. 10: 466. 1916.

Nome vulgar: coco-de-raposa.

Plantas 2,5-3,5 m alt., cespitosas. Caule ereto, até ca. 1,5 $\mathrm{m}$ alt., 6-7 cm diâm., normalmente oculto pelas bases peciolares. Folhas ca. 12, bainhas foliares mais pecíolo $26-42 \mathrm{~cm}$ compr., fibrosas; raque 74-89 cm compr.; folíolos verde-claros com ramento acastanhado ao longo da nervura mediana, muito flácidos, 63-77, irregularmente distribuídos, dispostos em diferentes planos, medianos 21,5-39 cm compr., 5-11 cm larg., acuminados, ápice assimétrico. Inflorescência: bráctea peduncular lenhosa, 4-25 cm compr., 5,5-7 cm larg., rostro 1-2 cm; pedúnculo $20-35 \mathrm{~cm}$ compr., raque $18-35 \mathrm{~cm}$ compr., raquilas 7-23, 11-25 cm compr.; flores estaminadas espiraladamente arranjadas na raquila, amarelas, ca. 8-3,1 mm, sépalas menores que $1 \mathrm{~mm}$, pétalas ca. 7,8 mm compr., 2,7 $\mathrm{mm}$ larg., ápice agudo ou acuminado, normalmente distintos, anteras ca. $3 \mathrm{~mm}$ compr., filete ca. $3 \mathrm{~mm}$ compr., pistilódio indistinto; flores pistiladas amarelo-escuro, 12,4-21 


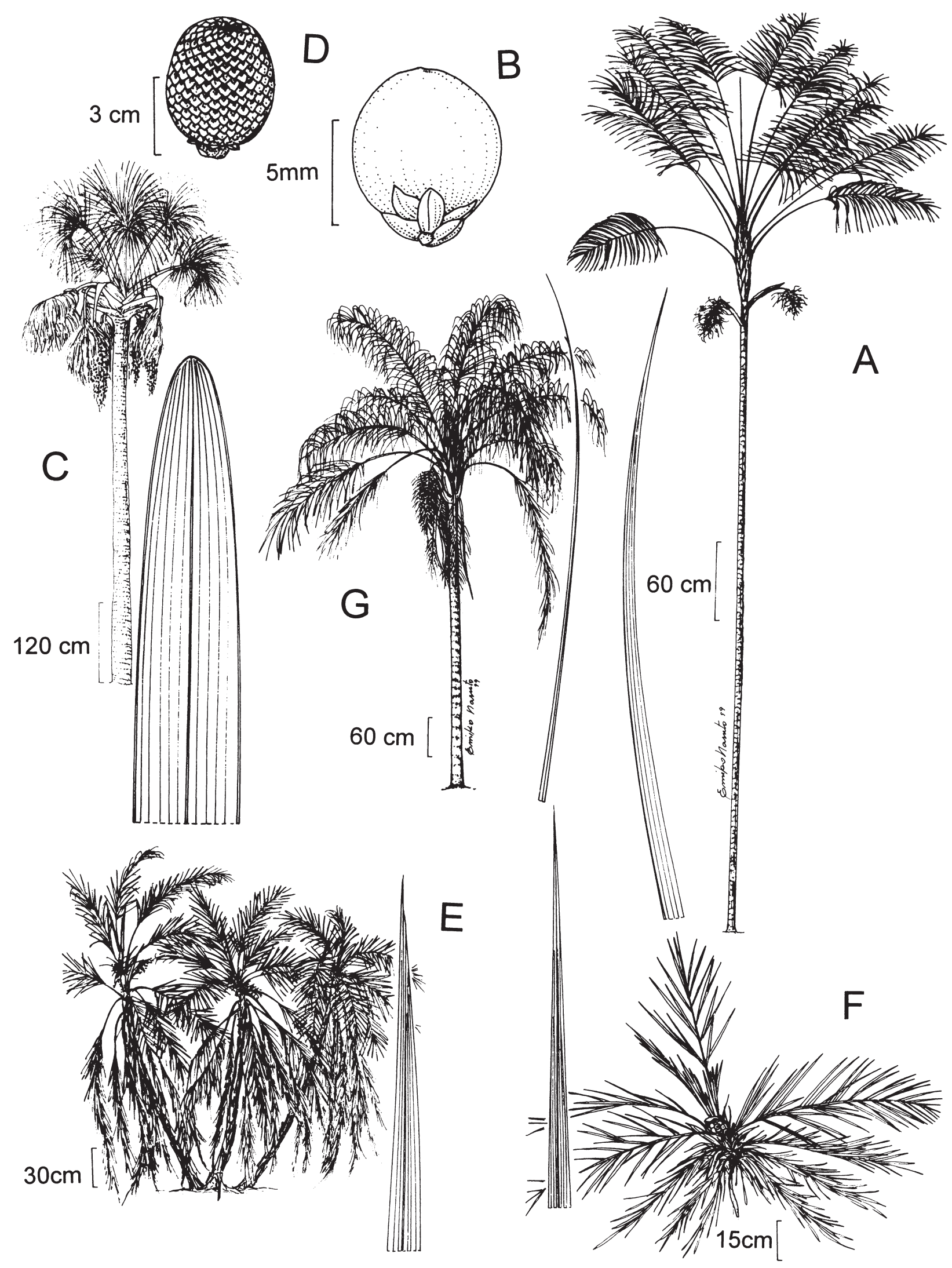

Fig. 2. PALMAE. A-B. Geonoma brevispatha: A. Hábito; B. Fruto. C-D. Mauritia flexuosa: C. Hábito; D. Fruto. E. Syagrus flexuosa: Hábito. F. Syagrus petraea: Hábito. G. Syagrus romanzoffiana: Hábito. 
mm compr., 5-8 mm larg., sépalas ca. 19,5 mm compr., 8 mm larg., pétalas ca. 11,4 mm compr., 5,3 mm larg., anel de estaminódios menor que $1 \mathrm{~mm}$ alt. Fruto 3,8-6,5 cm compr., 2,6-4,5 cm diâm., perianto castanho, ca. $27 \mathrm{~mm}$ compr., anel de estaminódios ca. 1,5 mm compr., pericarpo liso, glabro, esverdeado, menor que $1 \mathrm{~mm}$ espessura, mesocarpo fibroso carnoso, fortemente oleaginoso, ca. 9,6 mm espessura, endocarpo lenhoso, castanho, ca. 7,7 mm espessura, fibras dispersas; semente 1, endosperma homogêneo. (Fig. 2. E)

Marcato et al. 196, 207 (SPF); Mello-Silva et al. CFCR 9920 (MAC, SPF); Zappi et al. CFCR 12071 (SPF).

Espécie com distribuição pelos cerrados do Brasil Central . Em Grão-Mogol, ocorre normalmente em cerrado ou ainda em áreas de campo pedregoso, em altitudes de ca. $1000 \mathrm{~m}$. Coletada com flores e frutos em maio.

7.2. Syagrus petraea (Mart.) Becc., Agric. Colon. 10: 467. 1916.

Nome vulgar: coco-de-vassoura.

Plantas até 1,5 m alt., solitárias. Caule subterrâneo. Folhas 4-7, bainhas foliares mais pecíolo 13-60 cm compr., fibrosas; raque $42-46 \mathrm{~cm}$ compr.; folíolos verdes adaxialmente e muitas vezes glaucos abaxialmente com ramento acastanhado ao longo da nervura mediana, 14-22, irregularmente distribuídos, dispostos em diferentes planos, medianos 12-31 cm compr., 0,8-1,5 $\mathrm{cm}$ larg., acuminados, ápice assimétrico. Inflorescência: profilo 7,5-9,8 cm, bráctea peduncular lenhosa, 13-29 cm compr. total, rostro $0,7-1 \mathrm{~cm}$; pedúnculo $12-17 \mathrm{~cm}$ compr., raque 7-9,2 $\mathrm{cm}$ compr., espiciforme, ou ramificadas e então raquilas menores que $2 \mathrm{~cm}$ compr. Flores estaminadas amarelas, 10-12 mm compr., 3,4-4,8 mm larg., sépalas 1,3-3,1 mm compr., 1-1,5 mm larg., pétalas 9,8-11 mm compr., 2,5-3,5 mm larg., ápice agudo ou acuminado, anteras ca. 4,5 mm compr., filete ca. 2,3 mm compr., pistilódio indistinto. Flores pistiladas amarelo-creme, 9,4-17,5 mm, sépalas ca. 9,4 mm compr., $6 \mathrm{~mm}$ larg., pétalas ca. $9 \mathrm{~mm}$ compr., $5 \mathrm{~mm}$ larg., anel de estaminódios ca. $1 \mathrm{~mm}$ alt. Fruto 1,5-3 compr., 1-2,3 cm diâm., perianto persistente castanho, ca. 1,7 cm compr., anel de estaminódios ca. $1 \mathrm{~mm}$ compr., epicarpo liso, glabro, verde, menor que $1 \mathrm{~mm}$ espessura, mesocarpo fibroso ca. $1 \mathrm{~mm}$ espessura, endocarpo lenhoso, castanho, ca. $2 \mathrm{~mm}$ espessura, fibras dispersas; semente 1, endosperma homogêneo. (Fig. 2. F)

Ferreira et al. 778 (RB); Marcato et al. 204, 205 (SPF); Martinelli 5881 (RB); Pirani et al. CFCR 13375 (MAC, SPF); Zappi et al. CFCR 13167 (MAC, SPF).

Espécie de ampla distribuição e variedade morfológica, segundo Henderson (1995) desde solitária a cespitosa. Ocorre no Brasil do Pará e Maranhão a São Paulo e no leste do Paraguai e Bolívia. É normalmente encontrada em áreas abertas (principalmente cerrados) e matas ralas, sobre solos arenosos (Glassman 1987, Henderson et al. 1995). Em GrãoMogol, aparece no cerrado, tendo sido coletada com flores e frutos imaturos em junho.

É extremamente parecida com Allagoptera campestris quanto ao hábito, mas facilmente diferenciada desta por apresentar espiga pouco densa, pois A. campestris apresenta inflorescência muito condensada, causando inclusive certa dificuldade na individualização das flores.

\subsection{Syagrus romanzoffiana (Cham.) Glassman, Fieldiana} Bot. 31: 382. 1968.

Nome vulgar: jerivá, coquinho, coco-catarro.

Plantas até $20 \mathrm{~m}$ alt., solitárias. Caule ereto, até ca. $18 \mathrm{~m}$ alt., $40 \mathrm{~cm}$ diâm., cinéreo claro. Folhas ca. 18, bainhas foliares mais pecíolo 87-100 cm compr., fibrosas; pecíolo ca. $115 \mathrm{~cm}$ compr.; raque 3,15-4,62 m compr.; folíolos verdes adaxialmente e muitas vezes glaucos abaxialmente tomentosos ao longo da nervura mediana, ca. 179, irregularmente distribuídos, dispostos em diferentes planos, medianos ca. $94 \mathrm{~cm}$ compr., 2,7 cm larg., acuminados, ápice assimétrico. Inflorescência: bráctea peduncular lenhosa, espessa, ca. $10 \mathrm{~mm}, 152 \mathrm{~cm}$ compr. total, rostro $15 \mathrm{~cm}$; pedúnculo $100 \mathrm{~cm}$ compr., raque ca. $88 \mathrm{~cm}$ compr., raquilas ca. 101, 30-45 cm compr. Flores estaminadas espiraladamente arranjadas na raquila, amarelas, ca. 9-10 mm compr., 5-6 mm, sépalas $1 \mathrm{~mm}$ compr., $1 \mathrm{~mm}$ larg., pétalas 9-12 mm compr., 2-3 mm larg., ápice agudo ou acuminado, normalmente distintas, anteras 4-6 mm compr., filete dorsifixo ca. $2 \mathrm{~mm}$ compr., pistilódio ca. $1 \mathrm{~mm}$. Flores pistiladas amarelas, $4 \mathrm{~mm}$ compr., $4 \mathrm{~mm}$ larg., sépalas ca. $4 \mathrm{~mm}$ compr., $4 \mathrm{~mm}$ larg., pétalas ca. $4 \mathrm{~mm}$ compr., 3,5 $\mathrm{mm}$ larg., anel de estaminódios ca. $1 \mathrm{~mm}$ alt. Fruto 2-3 cm compr., 1,5-2,3 cm diâm., perianto persistente castanho, ca. $7 \mathrm{~mm}$ compr., anel de estaminódios ca. $2 \mathrm{~mm}$ compr., epicarpo liso, glabro, amarelo-alaranjado, menor que $1 \mathrm{~mm}$ espessura, mesocarpo fibroso carnoso, mucilaginoso, alaranjado, ca. $7 \mathrm{~mm}$ espessura, endocarpo lenhoso, castanho, trivitado, ca. $5 \mathrm{~mm}$ espessura, com fibras dispersas, penetrando o endosperma; semente 1, endosperma ruminado. (Fig. 2. G)

Marcato et al. 200 (SPF).

Material complementar: Minas Gerais, Diamantina, Marcato et al. 73 (SPF); Joaquim Felício, Marcato et al. 110 (SPF).

Sua ocorrência como espécie nativa vai desde a Bahia até o Rio Grande do Sul, aparecendo ainda no leste do Paraguai e Argentina. Trata-se na verdade de espécie de grande amplitude ecológica, ocorrendo em Mata Atlântica, matas ripárias, matas mesófilas e até beira de mangue (Reitz 1974, Henderson et al. 1995). Em Grão-Mogol, aparece sempre em matas ou margens de cursos d'água. 